\author{
Military Technical College \\ Kobry Elkobbah, Cairo, \\ Egypt.
}

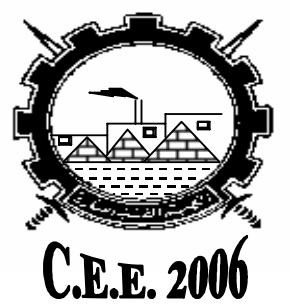

$3^{\text {rd }}$ International Conference

On

Chemical \& Environmental

Engineering

\title{
STUDYING OF THE THERMAL OBSCURING POTENTIALS OF SOME MINERAL DUSTS
}

\author{
Abd-Elmagid M. K. *, Fayed M. Sh. *, Ramzy H. *, and Milliegy T. *
}

\begin{abstract}
The advent of imaging seekers in the 8-12 $\mu \mathrm{m}$ bands poses a new challenge in the area of infrared countermeasures. Area-extensive infrared countermeasures will be necessary to defeat these new seekers. One effective component of these countermeasures will be infrared airborne obscurants, particles, essentially removing the original target from the imager's field.

The experimental studies concern with investigating the thermal screening potentials of some mineral dust, which are commercially available and unhazardous.

The smoke was generated pneumatically within a designed smoke tunnel equipped with means for measuring the surrounding meteorological parameters such as the ambient temperature, and relative humidity. The thermal obscuring potential of the smoke cloud was thermally tested by using a thermal camera attached to a video recorder and a data processing system. The effect of the smoke cloud on the attenuation of the infrared radiation emitted from a selected target was recorded, analyzed and explained.
\end{abstract}

The experimental results indicates the capability of experimentally studying the potential of various mineral dust as infrared obscurants

\section{KEY WORDS}

Infrared countermeasures, powder, screening, smoke, obscurants

\footnotetext{
* Egyptian Armed Forces.
} 


\section{INTRODUCTION}

Obscurants are man-made or naturally occurring particles suspended in the air that block or weaken the transmission of a particular part or parts of the electromagnetic spectrum, such as visible light, or infrared (IR) [1].

Sensory equipments (include the human eye, viewers, vision enhancement devices, trackers, and seekers) require a certain amount of energy (a minimum threshold) before they can perform their functions. A sensor will also fail to function if the level of energy, in the wavelength range that sensor is designed to work within, is too great (a maximum threshold) [2].

Bodies with a temperature greater than absolute zero emit electromagnetic radiation. Infrared radiation arises from the viberational and rotational motions of atoms and molecules in the emitting substance [3]. The character of radiation depends on the physical state of the source. Emission spectra of liquids and gases are characteristically lines or bands of discrete wavelength while solids, in most instances, radiate in a broad continuous spectrum [4]. If the material allows all possible transitions (thermal excitation of molecules), each atom provides a certain amount of radiation energy which statistically can take all possible values; the wavelength distribution will therefore be uniform and the radiation is then said to have a continuous spectrum [5]. The absorption of radiation by matter results in the apposite process, the absorption being more or less selective, depending on the wavelength and material. All bodies radiate copiously at these so-called normal temperature [6].

Tactical military electro-optics (EO) wavelength range encompasses the portion of the electromagnetic spectrum from approximately 0.4 -micrometer wavelength to 15 micrometers. There are two atmospheric windows in the range 3-5 um and 8-12 um and extensively used by electro-optics systems. The EO sensing and guidance system technology can be divided into three broad classes of devices non-imaging IR systems, Imaging IR systems, and Laser guidance system [7]. Whatever the advent of military electro-optic systems and their guidance systems, The working key of all the advent systems in the present and future; depend totally on the sensing of the received infrared photons which emitted from the target. If these photons are prevented to reach, the detection systems of the most advent electro-optic system will not sense the target.

One effective component of these area- extensive IR countermeasures could be obscurants. In studying the thermal attenuation of infrared radiation, which emitted from an object received by sensor through obscurant cloud, there are two primary processes that affect the thermal transmission of infrared radiation: absorption, and scattering. The effect of these two factors is both a reduction in the thermal (infrared) photons that reaches the sensor from the target [8]. 
Airborne obscurants could be considered as common name for most mechanical smoke systems. Obscurant particles are, by necessity, high-aspect ratio, electrically conductive fibers or flakes with small minor dimensions (nano-particles are interesting candidates) [9]. Metal flakes of copper or aluminum composition of submicron thickness and multi-micron lateral face dimensions is recognized to be a potential source for an infrared screening cloud for military purposes. The metal powder is packed in a camouflage system such as a canister, missile, rocket or a gas generator and dispersed in the atmosphere [12].

\section{EXPERIMENTAL WORK}

\subsection{Chemicals}

All the chemicals used in this experimental work were of the commercial grade. They were used directly without any purification or treatment. These chemicals and their toxicity limits are shown in the following table (2.1). The choice of the investigated powders was based on recent study of obscurant materials, the toxic hazards, explosion hazards, availability, and economic aspects. Calcium carbonate and talc are inflammable and do not form explosive mixture with air but ultra fine carbon black may be ignited or exploded in air at temperature above $250^{\circ} \mathrm{C}$ [15-16]. These chemicals are available and with acceptable toxicological properties, since their limits of human exposure are lower than other chemicals used in traditional pyrotechnical smoke mixtures [18-19].

\subsection{Instruments}

The used instruments during different steps of the experimental work are illustrated in table (2.2). Complete specification, effective working ranges, and available diagrams of the used instruments are illustrated during the description of each step of the experimental work. The thermal characteristics of the produced cloud of smoke were measured by thermal imager model 760 LW Inframetrics of spectral range from 8$12 \mu \mathrm{m}$. It was equipped with TV \& videocassette recorder model Panasonic TC4SV10S to record the thermal image of the infrared black body radiator model Graseby201/546, which was taken to be an ideal target of absolute calibration accuracy and temperature stability $\pm 2^{\circ} \mathrm{C}$. Thermal characteristics and data were processed and analyzed with IBM computer model 300PL PIII series, high performance $1.2 \mathrm{GH}$ processor. The relative humidity values were measured by digital thermo-hygrometer model TFA 4001. Air velocity within the tunnel was measured by wind velocity meter model Waren $\mathrm{H} 128$. Weighing was performed using digital analytical balance type Stanton digital balance model 351BR. Drying was carried out by drying oven of type Veb-mlw model WS3.

\subsection{Experimental Setup}

Experimental setup consists mainly of specially designed smoke tunnel, thermal imager, data acquisition system, and infrared black body. The smoke tunnel used for testing the smoke powders was specially designed and constructed for the purpose of smoke testing; its basic specifications are given in other reference [20]. The smoke was generated pneumatically in the tunnel by dispersion of the powder sample within sample holder which made of PVC. Figure (2.1) shows dimensional disassembly and 
assembly drawing of the sample holder. The maximum mass could be loaded in this holder was about $100 \mathrm{~g}$. The infrared black body radiator was used to represent a field target. The thermal imager and the accompanied devices for recording and processing were placed at the other end. An air curtain is applied in front of them to prevent the smoke from diffusion outside. The effect of smoke in reducing temperature and radiation level of the infrared black body radiator with time was recorded, graphed, and analyzed for each smoke sample. The setup used for measurements is illustrated in figure. (2.2).

\subsection{Experimental Evaluation of Obscuring Efficiency of Smoke Powders.}

\subsubsection{Preparation of Smoke Powder Samples}

The smoke samples before testing were dried in drying oven at $110^{\circ} \mathrm{C}$ for $5 \mathrm{hrs}$ and then cooled till reaching constant weight. Particle size of the smoke powder was analyzed by $90 \mu \mathrm{m}, 54 \mu \mathrm{m}$ and $20 \mu \mathrm{m}$ sieves and Dental vibrator model DV34 The smoke samples of calcium carbonate and talc were weighed with the following masses, 15.g, $25 \mathrm{~g}, 50 \mathrm{~g}, 75 \mathrm{~g}$, and 100.g.. While, carbon black powders are weighed with the following masses, $1.5 \mathrm{~g}, 2.5 \mathrm{~g}, 5 \mathrm{~g}, 10 . \mathrm{g}, 15 . \mathrm{g}$, and 25.g. Five samples were prepared, since each experiment was repeated five times.

\subsubsection{Testing of Smoke Powder Samples}

The sample under test was placed in the sample holder and at the same time, the smoke tunnel circulation system and the videocassette recorder are turned on. Air outlet from the tunnel blower disperses the smoke powder sample in the sample holder pushing it into the smoke tunnel in the front of the infrared black body radiator. Consequently, the smoke cloud propagated in the tunnel in front of the black body. The change in the observed temperature of the black body and its thermal image disappearance is recorded on the video tape during the propagation of the smoke cloud in the tunnel. The setup is turned off when the observed temperature of the infrared camera reaches its initial value before testing. Each composition was tested five times to minimize the experimental error.

\subsubsection{Data Analysis}

The data was gathered by playing the videotape in a slow motion. And the variation in temperature of the infrared radiator caused by the smoke sample was tabulated with time. The thermal transmittance of infrared radiation in the range of 8-14 micrometer through the smoke cloud is calculated. and presented in figures 3.1, 3.2, 3.3, and 3.4.

\section{RESULTS AND DISCUSSION}

Five different weights of smoke powder were chosen to produce different intensity of smoke when dispersed in the tunnel. Namely, 15, 25, 50, 75, and 100.g of the powders were loaded in the sample holder which corresponds to maximum smoke concentrations of $1.7,2.8,5.7,8.5$, and $11.3 \mathrm{~g} / \mathrm{m}^{3}$ respectively. The experiments 
were carried out in the smoke tunnel of total volume $8.85 \mathrm{~m}^{3}$, at $18^{\circ} \mathrm{C}$ ambient temperature and relative humidity $35 \%$. The black body radiator was set at $100^{\circ} \mathrm{C}$. These proposed smoke concentrations were estimated by dividing the mass loaded in the smoke tunnel by its total volume, assuming that the maximum thermal attenuation occurs when the mass loaded is dispersed homogeneously in the tunnel neglecting any losses. The tested amounts of carbon black were 1, 2.5, 5, 10, 15, and $25 \mathrm{~g}$, which correspond to maximum proposed smoke concentrations $0.11,0.28$, $0.56,1.13$, and $1.7 \mathrm{~g} / \mathrm{m}^{3}$ respectively. Two datums were selected at $80 \%$ and $90 \%$ thermal attenuation to compare between the tested samples.

It was found that thermal transmittance decreases during the propagation of the smoke cloud in the smoke tunnel due to the increase in concentration of the smoke materials. The minimum thermal transmittance occurs during experiment when the mass loaded in the tunnel achieves its maximum concentration, assuming homogenous distribution of the smoke cloud in the tunnel. After achieving maximum concentration of the smoke material, the concentration decreases due to gravitational sedimentation and so the thermal transmittance increases again. The obtained results are summarized in table (3.1). The obtained trends are shown in figures (3.1) to (3.3).

Figure (3.1) shows the effect of calcium carbonate smoke clouds produced by different masses dispersed in the smoke tunnel on the thermal transmittance of infrared radiation. The particles' size of the tested powder was $<20 \mathrm{um}$. By increasing the amount of calcium carbonate powder loaded in the sample holder from 15 to $100 \mathrm{~g}$, the maximum attenuation of thermal radiation of the black body augments from $32 \%$ to $88.3 \%$ with a corresponding increase in the duration of this maximum attenuation from 0.8 to $2 \mathrm{sec}$ respectively, and increasing the obscuring rate from $2.5 \mathrm{~S}^{-1}$ to $6.9 \mathrm{~S}^{-1}$.

The same procedures are repeated with talc powder and the results are shown in figure (3.2). The thermal attenuation augments from $30 \%$ to $78 \%$ with a corresponding increase in the duration of this maximum attenuation from 1.8 to $3 \mathrm{sec}$ respectively, and increasing the obscuring rate from $2.3 \mathrm{~S}^{-1}$ to $6 \mathrm{~S}^{-1}$.

By investigating the effect of different masses of carbon black on thermal transmittance, higher extent of attenuation was achieved as shown in figure (3.3). As the tested masses increases from one to $25 \mathrm{~g}$, the maximum thermal attenuation increased from 40 to $100 \%$ with corresponding increase in duration of these maximums attenuation from 3.1 to $7.7 \mathrm{sec}$, and increasing the obscuring rate from $3.1 \mathrm{~S}^{-1}$ to $7.7 \mathrm{~S}^{-1}$.

Table (3.1) represents a review of the obtained results after testing of calcium carbonate, talc, and carbon black. It shows the variation of the maximums thermal attenuation and its duration periods with the masses loaded. It was found that, the 
maximum attenuation achieved by calcium carbonate, talc, and carbon black were $88.3 \%, 78 \%$, and $100 \%$ respectively; which correspond to masses of the disseminated powders in the tunnel $100 \mathrm{~g}, 100 \mathrm{~g}$, and $10 \mathrm{~g}$ respectively. In addition to that, the increase in smoke concentration decreases the thermal transmittance depending on the smoke composition. The thermal transmittance decreases to 0.35 or less corresponding to only $3 \mathrm{~g} / \mathrm{m}^{3}$, and the rest of the transmittance decreases to reach zero corresponding to smoke concentrations up to $11.33 \mathrm{~g} / \mathrm{m} 3$.

Figure (3.4) shows the effect of different smoke concentrations of calcium carbonate, talc powder, and carbon black on the transmittance of the infrared radiation of a black body radiator at $100{ }^{\circ} \mathrm{C}$, the relative humidity was $35 \%$ and the ambient temperature was $18^{\circ} \mathrm{C}$. It was found that calcium carbonate achieving minimum thermal transmittance. The minimum thermal transmittance achieved by calcium carbonate, talc, and carbon black were $0.1,0.22$, and zero respectively. The minimum smoke concentration of carbon black sufficient for $80 \%$ thermal attenuation is 16 times lower than calcium carbonate. Only $1.23 \mathrm{~g} / \mathrm{m}^{3}$ of carbon black is sufficient to achieve $100 \%$ thermal transmittance attenuation.

\section{CONCLUSIONS}

The experimental results indicate the capability of experimentally studying the potential of various powders as infrared obscurants The main conclusions of the present work are:

(1) Commercially available mineral dusts such as carbon black, calcium carbonate and talc powder can be used in generation of aerosols, capable of thermal radiation attenuation.

(2) Carbon black exhibits the highest thermal attenuation, the next is calcium carbonate and then talc powder

(3) The increase in smoke concentration leads to decrease in thermal transmittance

\section{REFERENCES}

[1] Brian A. B., "Smoke and Obscurant Operations in a Joint Environment", Research Report, Air Command and Staff College, Air University, United States Army, 1998.

[2] Lewis J. P. "Electro Optics", John Wiley \& Sons, 1985.

[3] Goussorgues G.; "Infrared Thermograph"; Chapman and Hall Press, 1998

[4] Chrzanowski K. "Radiometry in Military Applications" Proceeding of SPIE International Society of Optical Engineering V4517, P 1-15, 2001.

[5] Meyers R. A. "Encyclopedia of Analytical Chemistry: Application, Theory and Instrumentation", Vol. 1, John Wiley Press, 2000.

[6] Branson A.M., "Infrared: A Handbook for Applications", Plenum Press, 1966.

[7] David W. H.,"Light scattering Theory", Florida University, 2004.

[8] Ahmed A. A.;" IR/Laser Guidance and Image Tracking Systems and Their Countermeasures", Ph.D., M. T. C., Cairo,2001 
[9] Wulvik E., "Arrangement in Smoke Camouflage System", Patent Number: US 5233927, 1993.

[10] United Stats Department of Defense "Developing Critical Technologies/Science \& Technology (DCT/S\&T): Section 5: Chemical Technology", Defense Threat Reduction Agency, 2000.

[11] Annual Book of ASTM Standards, "Standard Tests Method for Ignition Temperature of Active Carbon", D3466, 1993.

[12] Greenwood N.N and Eanshaw A., "Chemistry of Elements", Pergmon Press, 1984.

[13] Richard J., and Lewis S. "Hazardous Chemicals Desk Reference", Fifth Edition, John Wiely Press, 2003.

[14] George W. "Handbook of Fillers", $2^{\frac{n d}{}}$ Edition, Chem. Tec. Publishing, 2000.

[15] Mansour A. A., "Military Application Of Polymeric Materials: The Use Of Polymeric Materials in Smoke Producing Agents", MSc., M.T.C, Cairo 1997. 
Proceeding of the $3^{\text {rd }}$ CEE Conference 16-18 May 2006

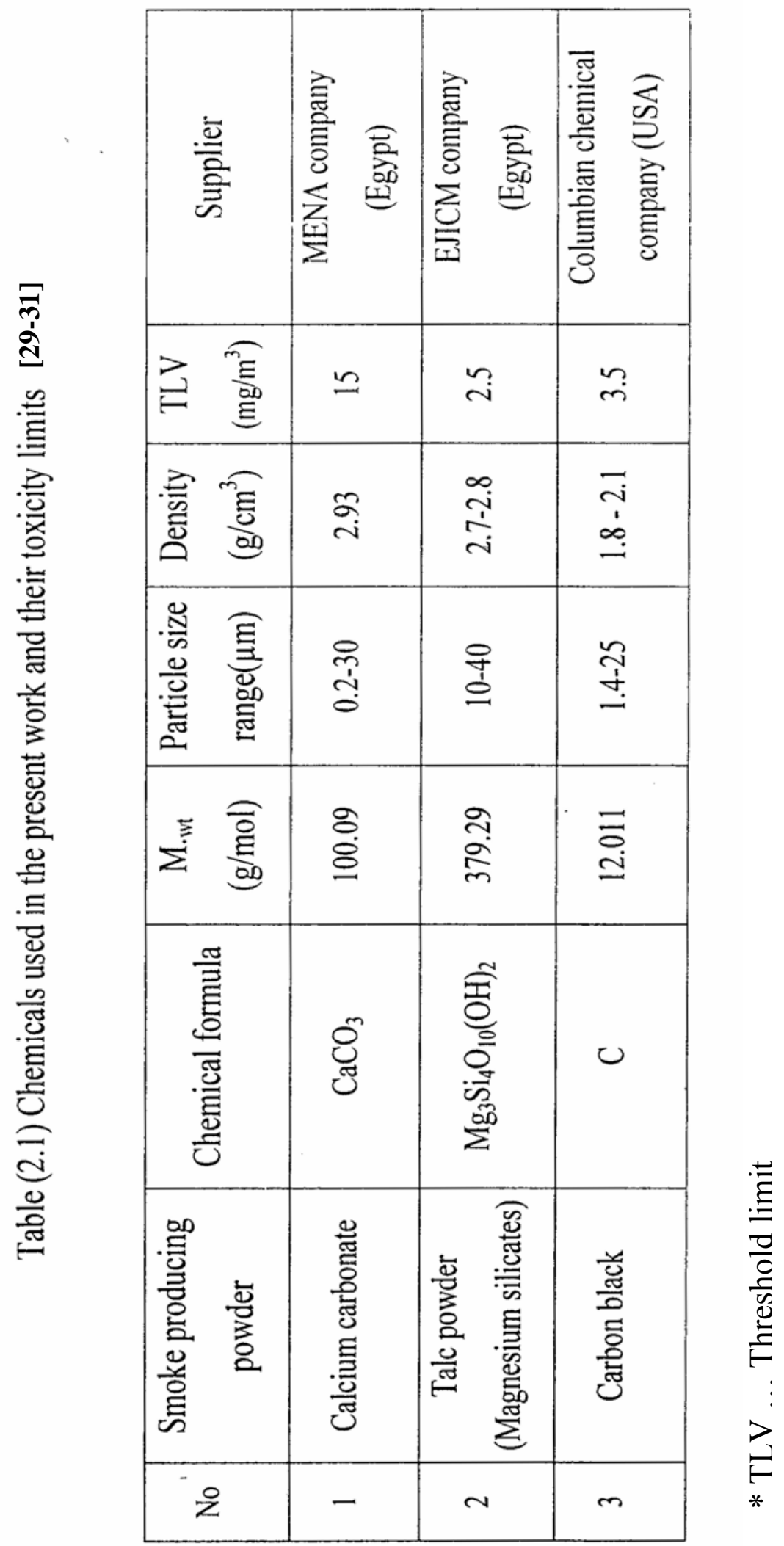




\begin{tabular}{|c|c|c|c|c|c|c|c|c|c|c|}
\hline Ð త్ర & \multirow{6}{*}{ 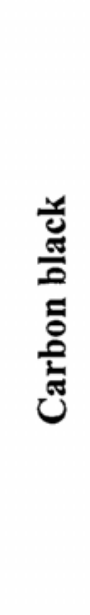 } & $\approx$ & 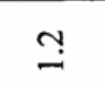 & $\stackrel{\infty}{\hat{n}}$ & $m$ & กี & $\stackrel{\infty}{i}$ & ○ & $\infty$ & 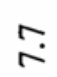 \\
\hline 总 & & $\cong$ & $\tilde{n}$ & $\stackrel{n}{\forall}$ & $\stackrel{?}{*}$ & $\tilde{n}$ & $\stackrel{1}{=}$ & 8 & $\simeq$ & 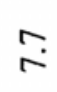 \\
\hline ప: & & 으 & $\tilde{n}$ & $\frac{n}{n}$ & $n$ & $\tilde{n}$ & $\stackrel{m}{=}$ & 8 & $r$ & $i$ \\
\hline בְ & & $n$ & $r$ & 유 & $\stackrel{n}{=}$ & $n$ & ڤั? & ֻั & 6 & ఫิ \\
\hline 丞 & & $\tilde{N}$ & i & i & i & i & $\stackrel{\infty}{\stackrel{\infty}{0}}$ & $\underset{\hat{\sigma}}{\tilde{b}}$ & $\tilde{n}$ & $\stackrel{q}{\dot{f}}$ \\
\hline 0 & & - & $!$ & 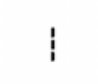 & 1 & 1 & $=$ & 웅 & $\nabla$ & $\vec{m}$ \\
\hline & & 8 & $i$ & i & $\mathbf{i}$ & i & $\stackrel{m}{\Xi}$ & $\infty$ & $m$ & 6 \\
\hline of tö & $\frac{\grave{c}}{\partial}$ & $\approx$ & I & I & 1 & 1 & $\dddot{\infty}$ & $\stackrel{\infty}{r}$ & $\stackrel{0}{i}$ & 6 \\
\hline & 을 & 으 & i & i & 1 & 1 & $\stackrel{0}{\dot{r}}$ & $m$ & $\stackrel{\Delta}{\sim}$ & $\stackrel{b}{\dot{r}}$ \\
\hline ఫై ఫ్రి & $\stackrel{\pi}{\sigma}$ & $\approx$ & i & i & i & 1 & $\stackrel{\infty}{i}$ & $\bar{n}$ & $\vec{i}$ & ले \\
\hline & & $\cong$ & i & i & i & i & $\Xi$ & 요 & $\stackrel{\infty}{-}$ & $\tilde{n}$ \\
\hline 0 & & ᄋ & $\infty$ & $\stackrel{m}{=}$ & i & 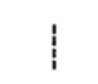 & $\stackrel{m}{\Xi}$ & $\mathfrak{\infty}_{\infty}^{\infty}$ & $\sim$ & $\underset{0}{\infty}$ \\
\hline & สํํㄹ & $\cong$ & $a$ & $\nabla$ & i & $i$ & $\dddot{n}$ & $\frac{\dot{\infty}}{\infty}$ & 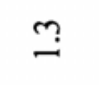 & กุ \\
\hline & ฮ & 오 & $i$ & i & $i$ & $i$ & ம) & $\curvearrowleft$ & $=$ & $\stackrel{\infty}{n}$ \\
\hline 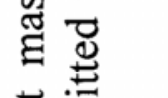 & $\frac{\bar{z}}{\pi}$ & $\approx$ & 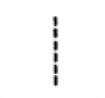 & 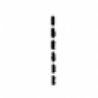 & 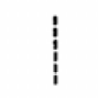 & & $\stackrel{\infty}{i}$ & $\stackrel{n}{n}$ & - & $\underset{\sim}{\sim}$ \\
\hline 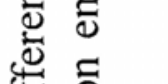 & & $\cong$ & 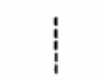 & 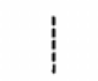 & 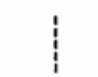 & 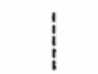 & $I$ & N & $\stackrel{\infty}{0}$ & $\stackrel{\sim}{\sim}$ \\
\hline 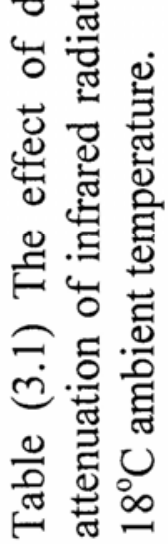 & 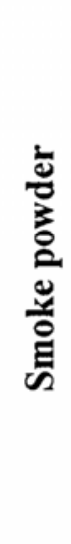 & 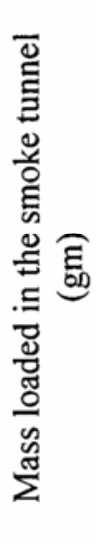 & 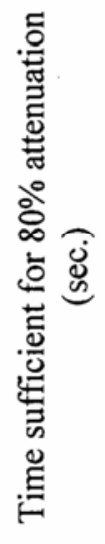 & 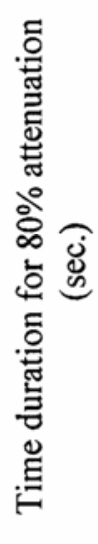 & 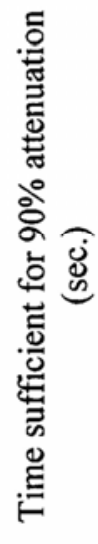 & 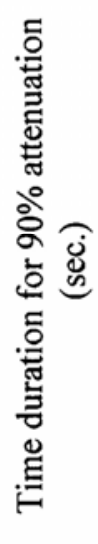 & 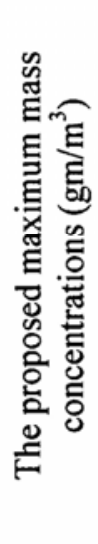 & 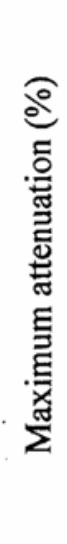 & 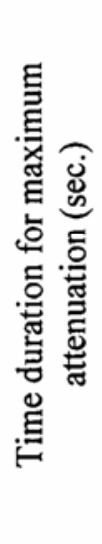 & 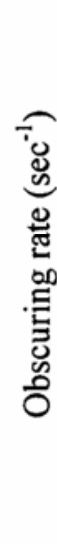 \\
\hline
\end{tabular}


Table (3.2) The attenuation of infrared radiation of a black body radiator at $100^{\circ} \mathrm{C}$ by calcium carbonate, talc powder, carbon black and binary mixtures of them at relative humidity $35 \%$ and ambient temperature was $18^{\circ} \mathrm{C}$.

\begin{tabular}{|l|c|c|c|}
\hline \multicolumn{1}{|c|}{ Smoke powder } & $\begin{array}{c}\text { Carbon } \\
\text { black }\end{array}$ & $\begin{array}{c}\text { Calcium } \\
\text { carbonate }\end{array}$ & $\begin{array}{c}\text { Talc } \\
\text { powder }\end{array}$ \\
\hline $\begin{array}{l}\text { Smoke concentration sufficient for 80\% attenuate } \\
\text { on. }\left(\mathrm{g} / \mathrm{m}^{3}\right)\end{array}$ & 0.49 & 7.56 & --- \\
\hline $\begin{array}{l}\text { Smoke concentration sufficient for 90\% attenuate } \\
\text { on. }\left(\mathrm{g} / \mathrm{m}^{3}\right)\end{array}$ & 0.52 & --- & --- \\
\hline Minimum thermal transmittance & zero & 0.12 & 0.22 \\
\hline $\begin{array}{l}\text { Minimum Smoke concentration sufficient for } \\
\text { maximum attenuation. }\left(\mathrm{g} / \mathrm{m}^{3}\right)\end{array}$ & 1.23 & 11.3 & 11.3 \\
\hline
\end{tabular}




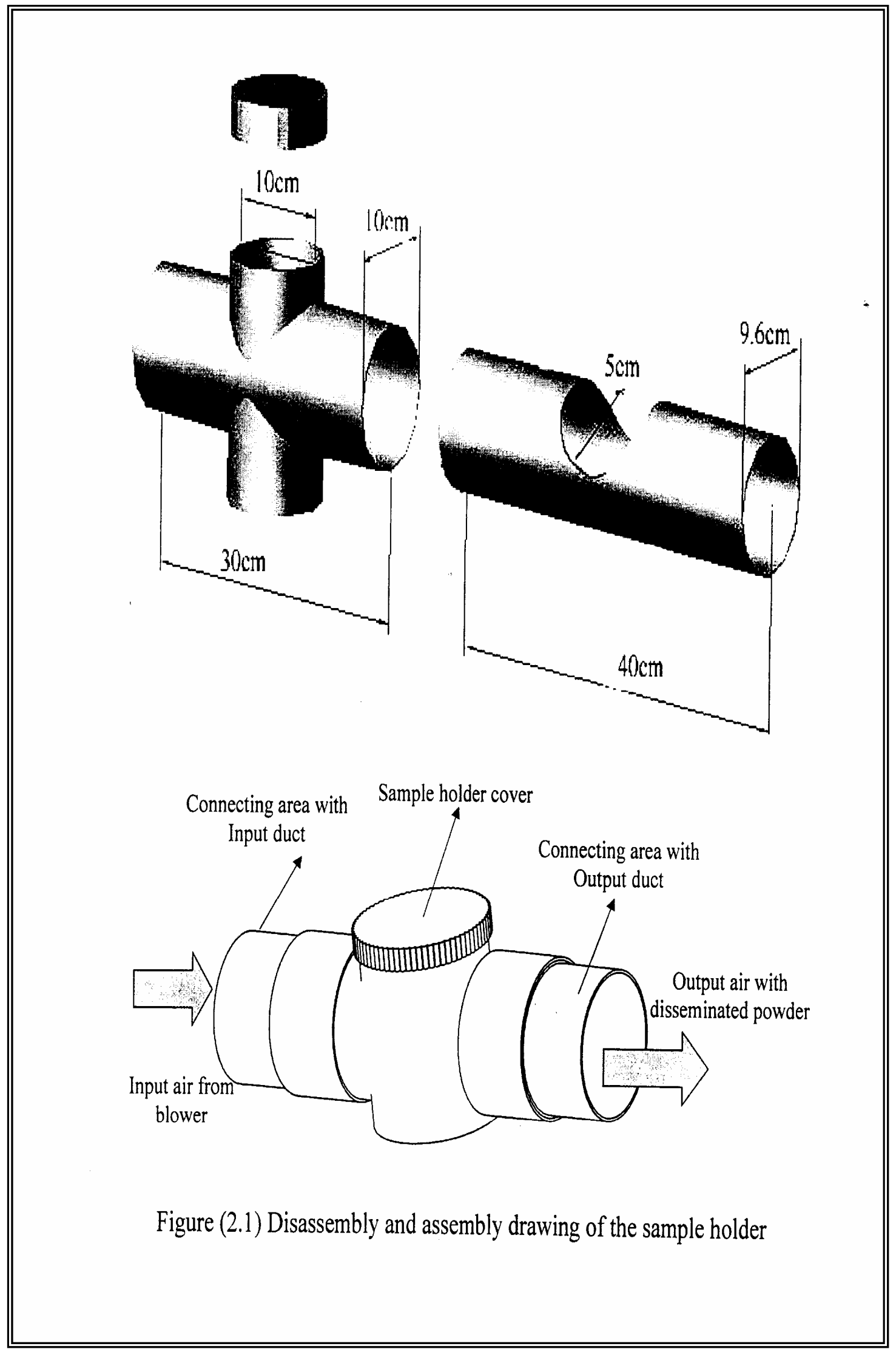




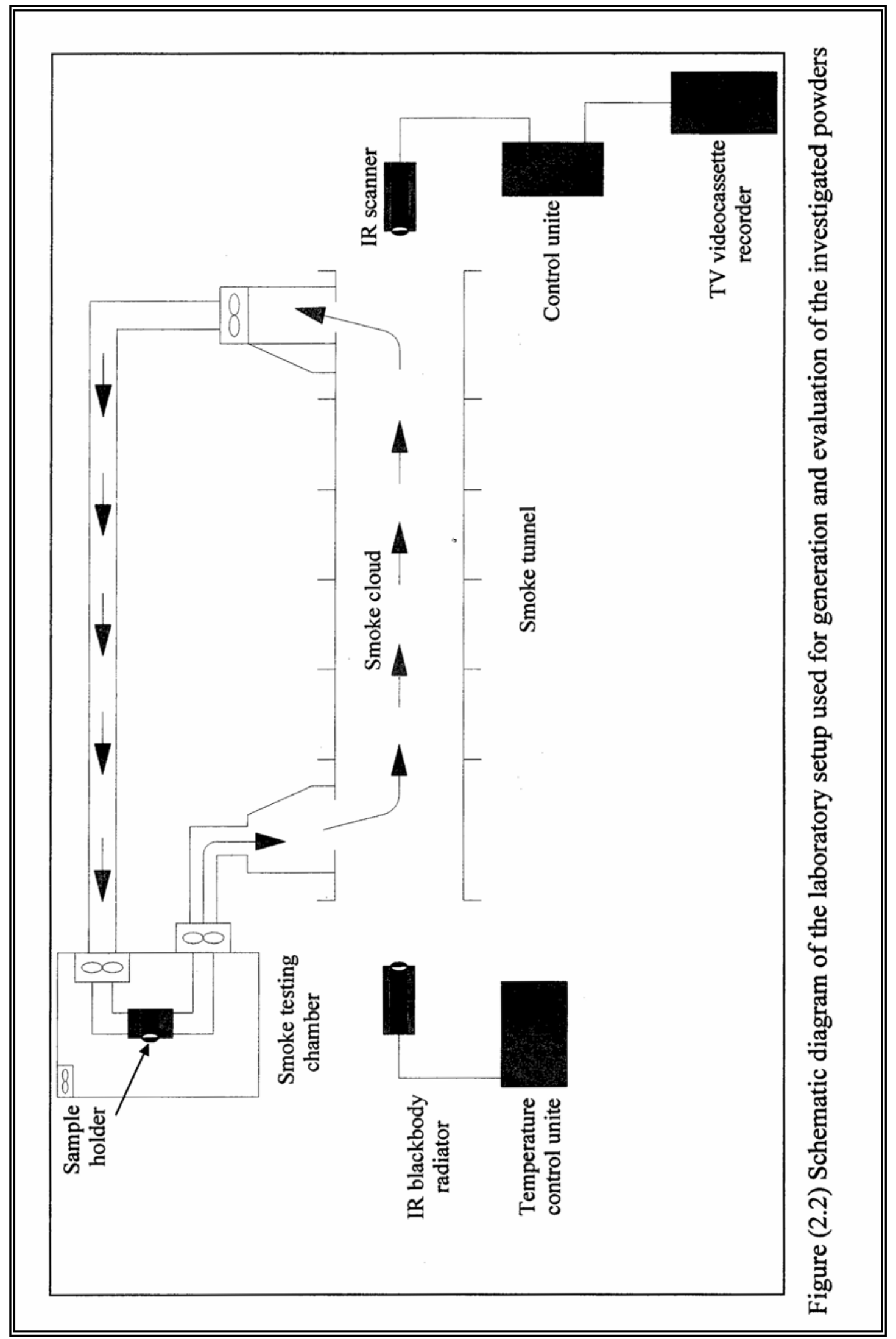




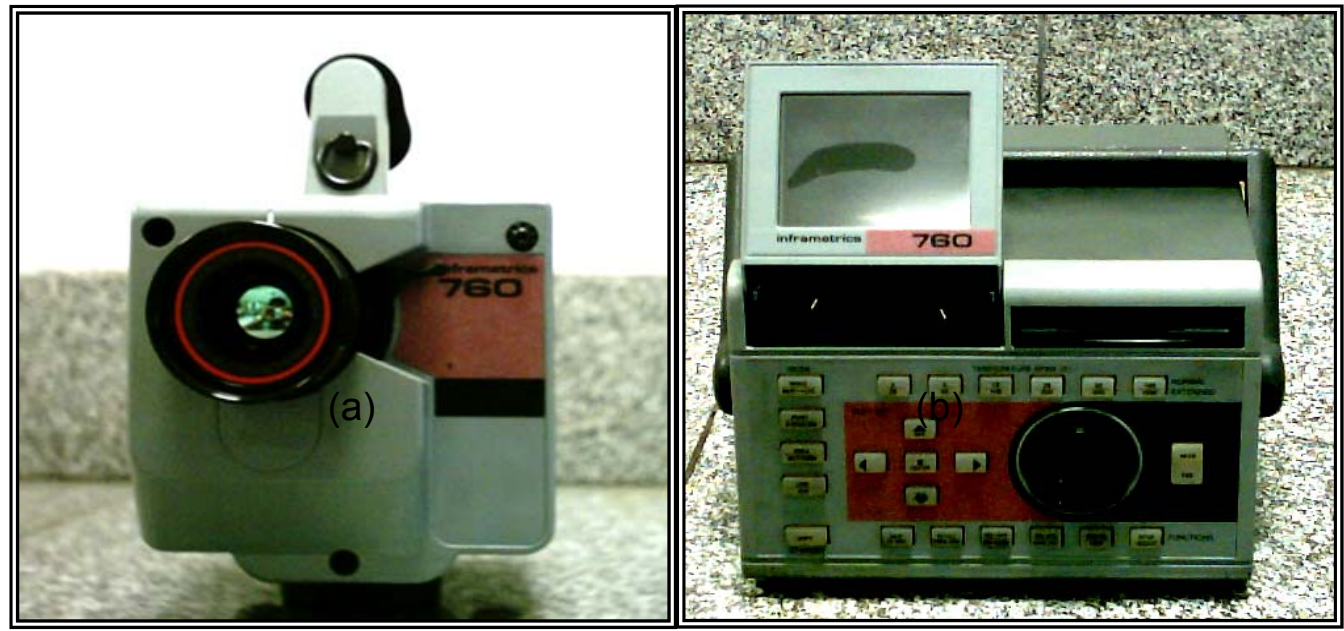

Figure (2.3) Inframetrics Infrared Radiometer model 760 IR Imaging Radiometer. (a) Inframetrics 760 thermal scanner. (b) Inframetrics thermal image-processing systems

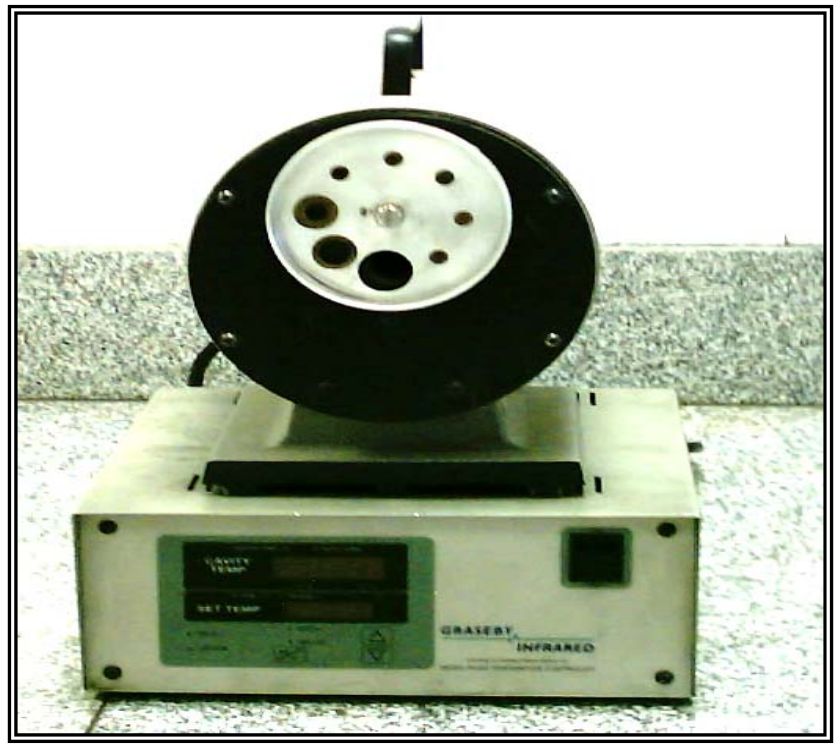

Figure (2.4) Graseby infrared black body IR radiator with temperature controlling unit 


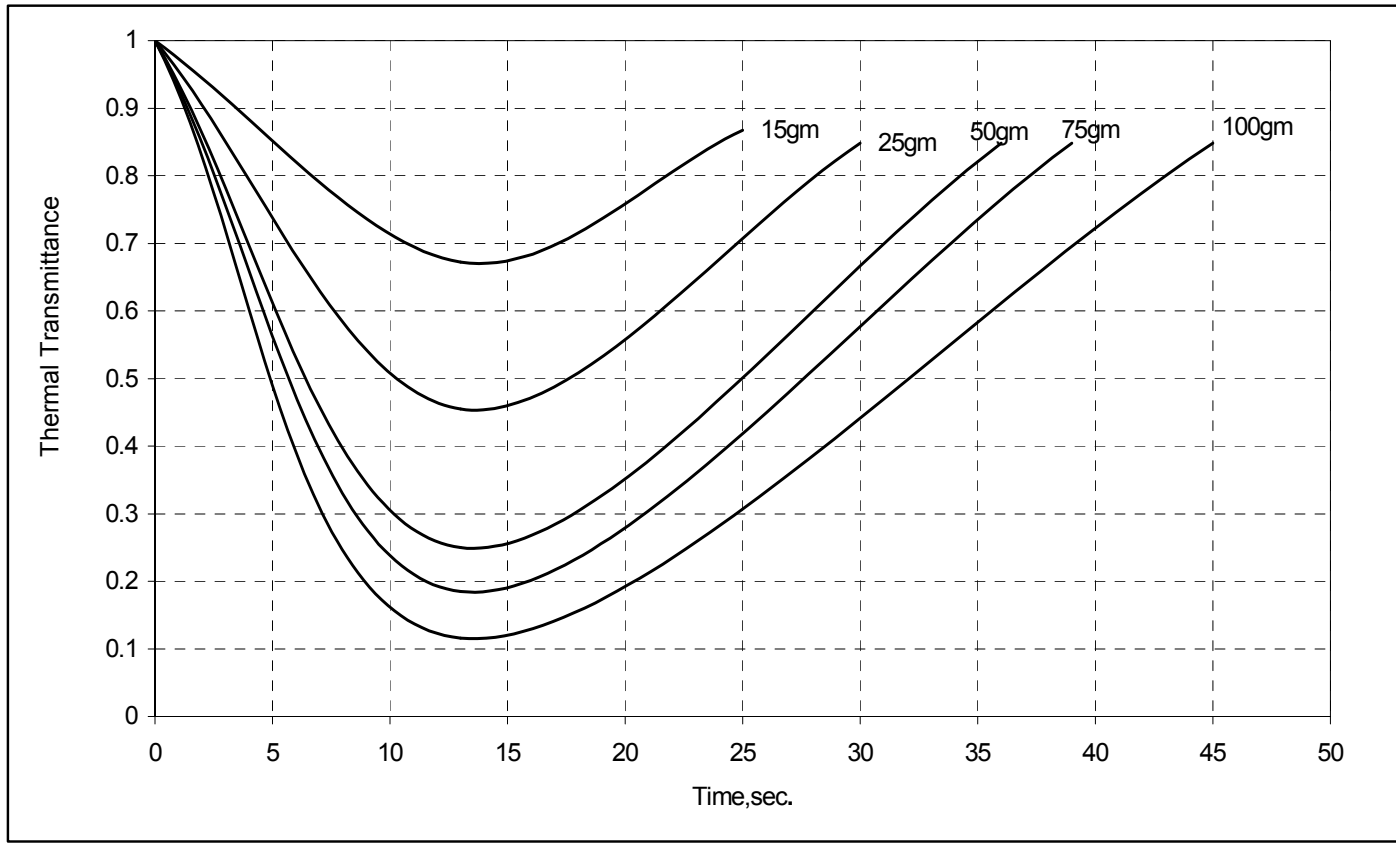

Figure (3.1) Attenuation of infrared radiation emitted from black body radiator at $100^{\circ} \mathrm{C}$ by calcium carbonate at relative humidity $35 \%$ and $18^{\circ} \mathrm{C}$ ambient temperature.

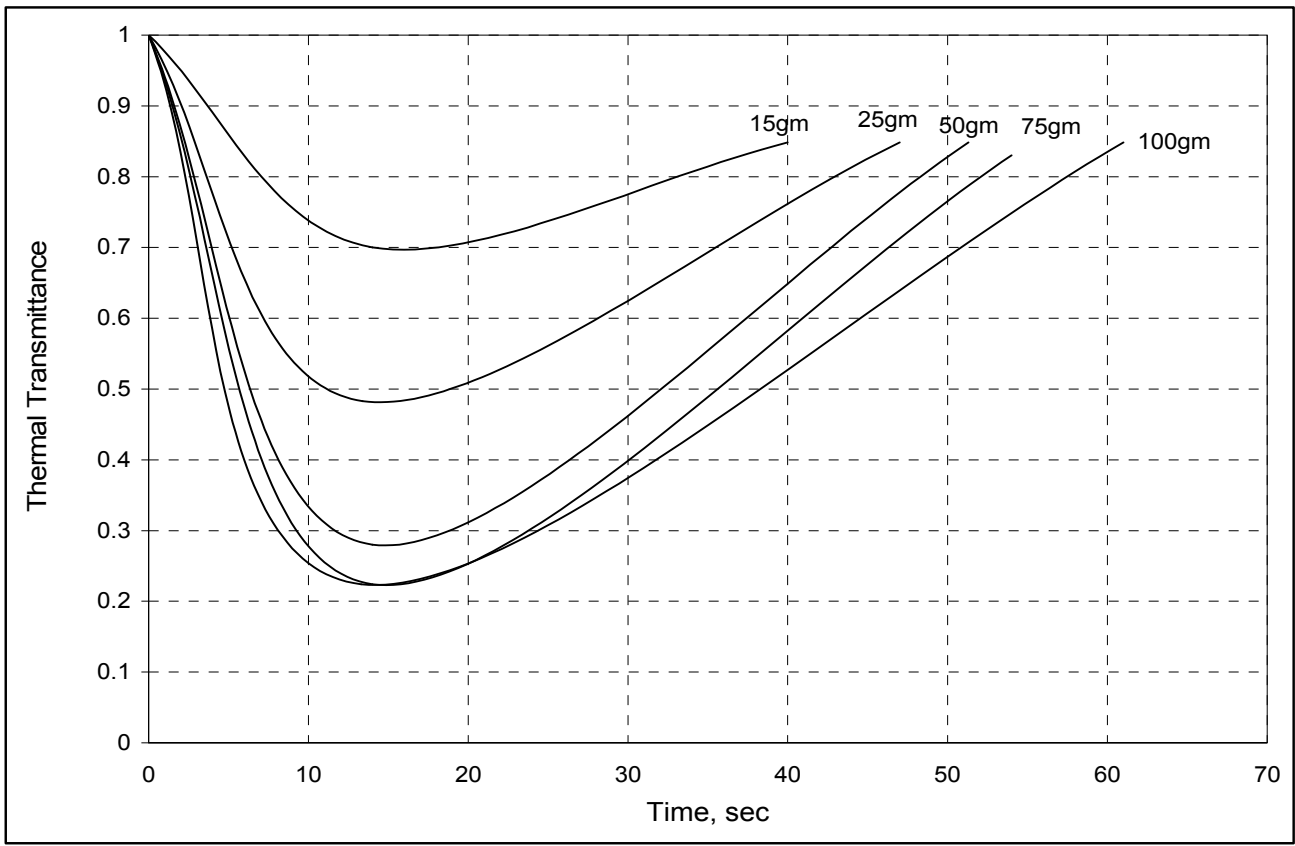

Figure (3.2) Attenuation of infrared radiation emitted from black body radiator at $100^{\circ} \mathrm{C}$ by talc powder at relative humidity $35 \%$ and $18^{\circ} \mathrm{C}$ ambient temperature. 


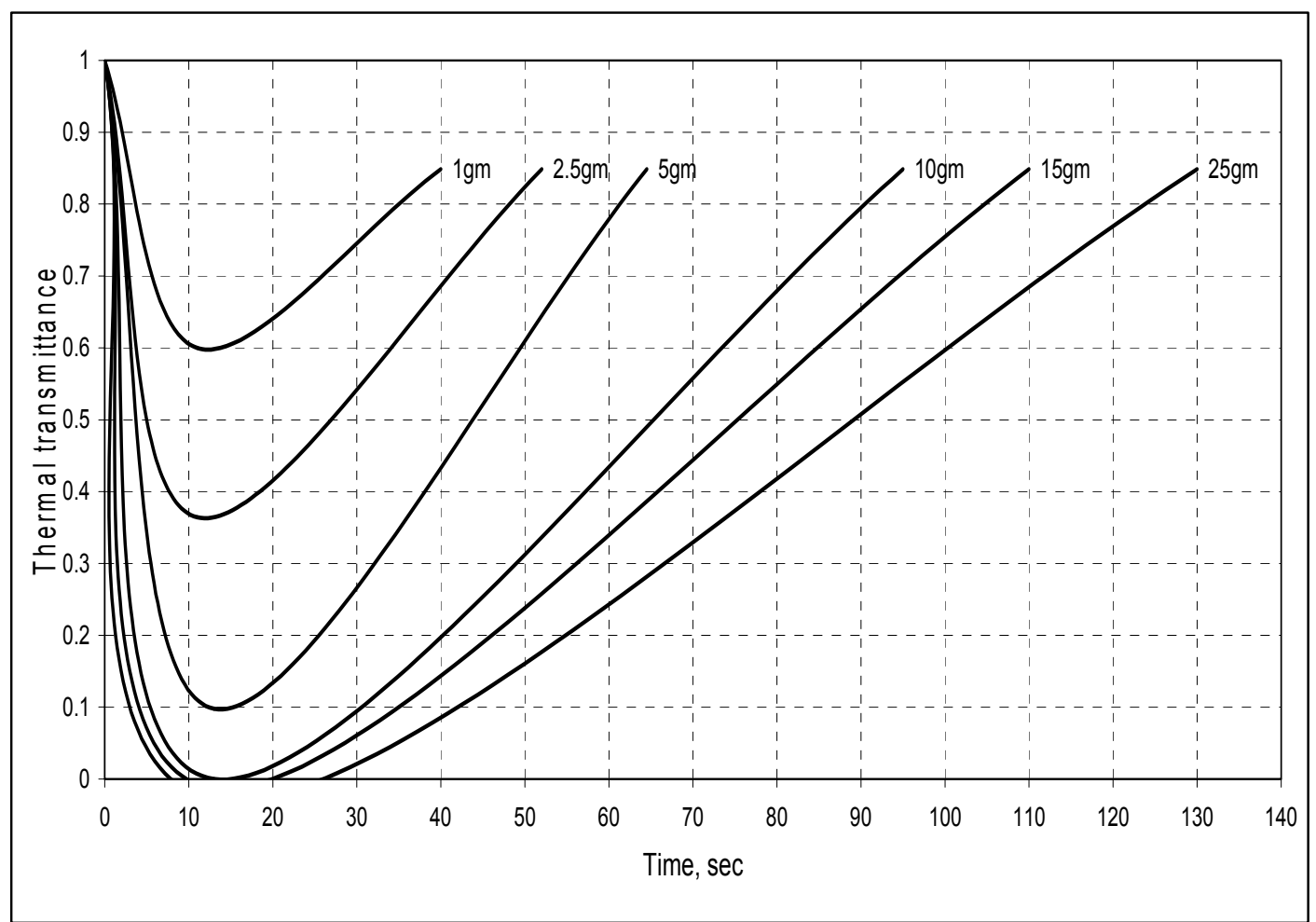

Figure (3.3) Attenuation of infrared radiation emitted from infrared black body radiator at $100^{\circ} \mathrm{C}$ by carbon black at relative humidity $35 \%$ and $18^{\circ} \mathrm{C}$ ambient temperature.

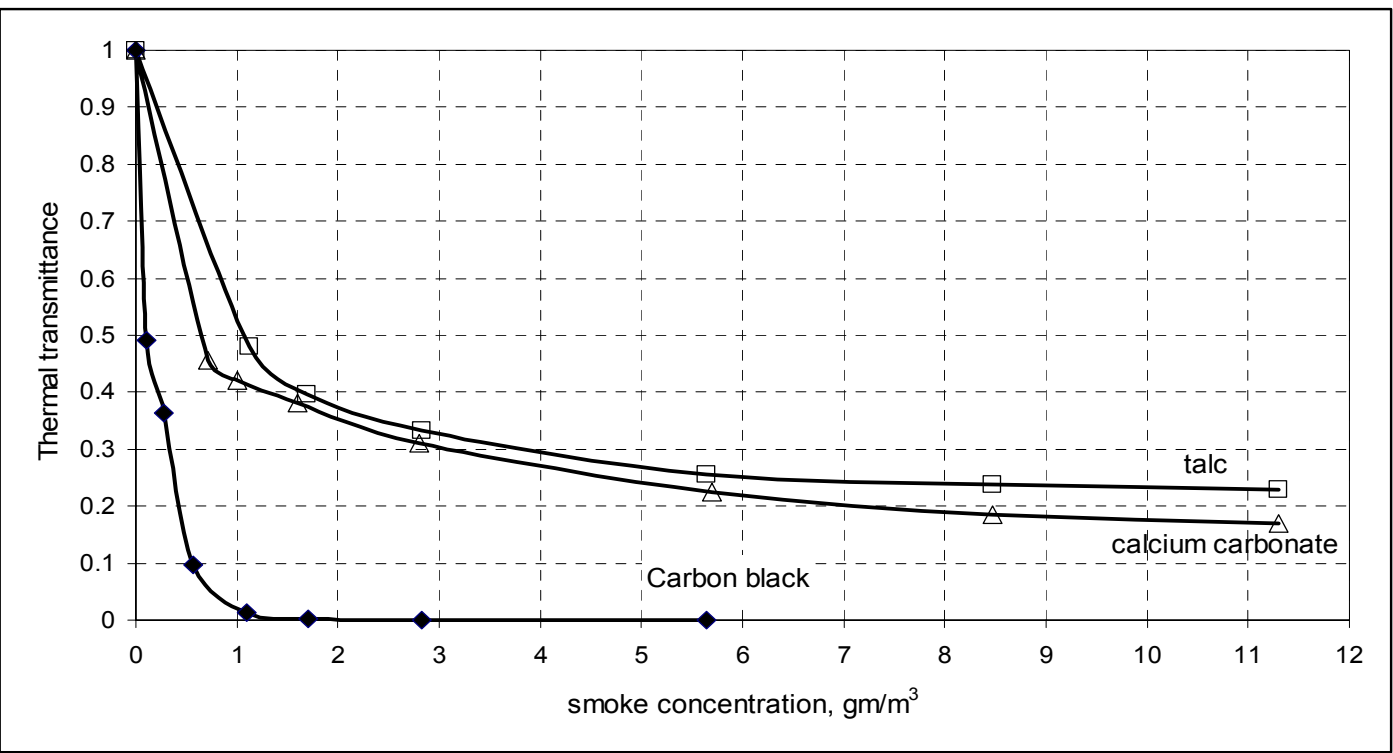

Figure (3.4) Effect of calcium carbonate, talc powder, and carbon black smoke concentrations on the transmittance of infrared radiation of black body at temperature $100^{\circ} \mathrm{C}$, at relative humidity $35 \%$ and $18^{\circ} \mathrm{C}$ ambient temperature. 